\title{
A percepção dos professores de escolas públicas de Educação Infantil
}

\author{
Maria Eleusa Montenegro ${ }^{1}$ \\ Aictyr Lomonte da Silva ${ }^{2}$ \\ Ana Regina Melo Salviano ${ }^{3}$ \\ Celeida B. Garcia Cintra Pinto ${ }^{4}$ \\ Elenice Ribeiro dos Santos ${ }^{5}$
}

\section{Resumo}

Este artigo apresenta os resultados da pesquisa acerca da percepção dos professores quanto às expectativas e necessidades da Educação Infantil em escolas públicas do Distrito Federal. Foi utilizado o método qualitativo, instrumentado por questionário. Concluiu-se que os professores estavam preparados para a docência e satisfeitos com a profissão escolhida. A realização do diagnóstico inicial da turma foi uma das dificuldades destacadas pelos professores, que acreditam que as relações interpessoais harmônicas entre professores, diretores, coordenadores, pais e alunos determinam a qualidade do trabalho pedagógico. Espera-se que este trabalho venha a contribuir para que haja mais reflexões acerca do ensino na Educação Infantil.

Palavras-chave: Educação infantil. Prática pedagógica. Escola pública. Formação do professor.

1 Pedagoga; orientadora educacional; administradora escolar; pós-doutora em Educação pela UnB; professora aposentada pela UFG; professora de Pedagogia do UniCEUB; líder do grupo de Pesquisa "Prática Pedagógica e Formação do Professor". memontenegro@ terra.com.br.

2 Pedagoga pelo UniCEUB, professora de Educação Básica da Secretaria de Estado de Educação do Distrito Federal. aictyr@yahoo.com.br.

3 Pedagoga; orientadora educacional; administradora escolar; mestre em Educação pela FE/UnB (Currículo e Metodologia de Ensino); professora aposentada da SE-DF; professora do UniCEUB do curso de Pedagogia, das Licenciaturas e do Ciclo Básico. ana_regina@ terra.com.br.

4 Pedagoga; orientadora educacional; administradora escolar; psicopedagoga; mestre em educação pela UCB-DF; professora aposentada pela SEC-DF; professora de Pedagogia e Licenciaturas do UniCEUB. celeidacintra@uol.com.br.

5 Aluna do Ensino Médio no Centro Educacional GISNO e bolsista júnior do UniCEUB/ FAP/CNPq. elenicerdr@gmail.com. 


\section{Situando 0 assunto}

A finalidade desta pesquisa é apresentar as necessidades e expectativas dos professores de escola pública de Educação Infantil e a formação do professor que pretende atuar nesse nível de ensino.

A Educação Infantil é aquela que atende pedagogicamente o período de vida escolar de crianças com idade entre 0 e 5 anos, isso com a implantação do Ensino Fundamental de nove anos. Entretanto, este trabalho enfatiza a faixa etária entre 3 e 5 anos de idade.

De acordo com a Lei de Diretrizes e Bases da Educação Nacional - LDB, Lei no 9.394/96 (BRASIL, 2011b), a instituição educacional que atende crianças de 0 a 3 anos é denominada creche, e a que atende crianças de 4 e 5 anos denomina-se infantil. Conforme Referencial Curricular Nacional de Educação Infantil (BRASIL, 2011c, p. 21),

[...] a criança como todo ser humano, é um sujeito social e histórico e faz parte de uma organização familiar que está inserida em uma sociedade, com uma determinada cultura, em um determinado momento histórico. É profundamente marcada pelo meio social em que se desenvolve, mas também o marca. (BRASIL, 2011b, p. 21).

A Constituição Federal da República de 1988 (BRASIL, 2011a) determinou, em seu art. 208, inciso IV, que a educação na faixa etária de 4 e 5 anos é dever do Estado e que esta responsabilidade caberia ao antigo Curso Normal (nível técnico) ou simplesmente Magistério de segundo grau.

Na LDB, n 9394/96 (BRASIL, 2011b), ficou determinado que todos os professores que atuassem na Educação Infantil deveriam ser graduados, pretendendo-se com isso garantir formação pedagógica mais qualificada e extensiva a esse nível de ensino, visto que é um período muito importante para o desenvolvimento e a aprendizagem. Nessa fase, deverão ser desenvolvidas nas crianças todas as dimensões que as constituem, isto é, cognitiva, afetiva, social, motora e psicológica. 
Desse modo, o objetivo geral deste trabalho foi investigar junto aos professores as expectativas e necessidades da Educação Infantil, verificando-se também a preparação desses profissionais para atuarem nesse nível de ensino. Os objetivos específicos pretenderam:

- investigar, junto aos professores, as expectativas e necessidades que emergem com relação à Educação Infantil;

- investigar os procedimentos didático-metodológicos utilizados pelos professores e os resultados pedagógicos até então alcançados;

- verificar a opinião dos professores quanto à preparação dos profissionais que atuam na Educação Infantil; e

- propor alternativas para aperfeiçoar o processo de formação do profissional da Educação Infantil, tendo em vista as expectativas da comunidade escolar do Distrito Federal.

\section{Os procedimentos metodológicos}

Esta pesquisa foi realizada em escolas públicas que atuam na área da Educação Infantil e, para obtenção de resultados mais esclarecedores, foram entregues aos professores de escolas públicas trinta questionários para respostas pessoais. A pesquisa desenvolveu-se em três etapas, assim organizadas: no primeiro momento, foi analisada toda a legislação acerca da Educação Infantil dos últimos anos, de maneira que se estabelecessem parâmetros de comparação com a realidade educacional. Na segunda etapa, foi realizada investigação in loco junto às escolas públicas de Educação Infantil do Distrito Federal, por meio de questionários semiestruturados, como forma de verificar as expectativas e as necessidades de cada escola. $\mathrm{Na}$ última etapa, discutiram-se os dados coletados, relacionando-os à legislação pertinente e à literatura atual acerca do assunto, chegando-se aos resultados do trabalho. A partir daí, foram propostas alternativas compatíveis com os anseios e os interesses emergentes na tentativa de, gradativamente, qualificar a Educação Infantil nas instituições, bem como na formação dos profissionais para a área.

Para análise e discussão dos dados, foram utilizados pressupostos das abordagens qualitativas e quantitativas, tendo sido adotados os pressupostos da episte- 
mologia qualitativa proposta por González Rey (2005, p. 5-8, grifo do autor), que a conceitua como sendo aquela que:

[...] defende o caráter construtivo-interpretativo do conhecimento, o que, de fato, implica compreender o conhecimento como produção e não como apropriação linear de uma realidade que se nos apresenta.

Nesse sentido, efetuaram-se a coleta de dados e a busca, em material bibliográfico - livros e artigos -, da legislação que trata do assunto e de conhecimentos acerca das expectativas e necessidades relacionadas à Educação Infantil, com vistas a tecer e a criar construção teórica a respeito.

Os dados coletados foram organizados de maneira a proporcionar apresentação e compreensão de mais qualidade, visando à análise e à discussão do conteúdo. Para isso, foram definidas algumas categorias, quais sejam: a caracterização dos participantes da pesquisa, o trabalho pedagógico, as relações interpessoais, a formação para o trabalho e a realidade escolar.

O questionário, instrumento utilizado na realização da coleta, foi elaborado com perguntas estruturadas e semiestruturadas, o que permitiu perceber a situação atual do grupo pesquisado e objetivou-se, na medida do possível, extrapolar a mera descrição do conteúdo do instrumento, aprofundando-se na interpretação das respostas e, assim, construir o conhecimento.

Verificaram-se também referências importantes que caracterizassem os participantes, como: idade, sexo, escolaridade e profissão que exercem.

\section{Análise e discussão dos dados: principais resultados}

\subsection{A caracterização das participantes da pesquisa na escola pública}

Todas as participantes que assinalaram o sexo no questionário (29) são do sexo feminino, porém, uma não assinalou tal item. Nessa perspectiva, Morettini (2000, p. 44) destaca que: 
[...] ser professora na área de Educação Infantil é uma ideia que não atrai as famílias das frações mais altas da classe média, ficando a profissão reservada para os setores mais baixos da classe, para quem esta área de atuação ainda pode significar opção de vida e, nesses setores, às mulheres.

Em relação à faixa etária das trinta docentes, nenhuma tinha menos de vinte anos; cinco estavam entre as faixas de 20 e 30 anos, quatorze estavam entre 31 e 40 anos, nove, entre 41 e 50 anos e duas já tinham entre 51 e 60 anos.

Apenas três professoras afirmaram ser muito valorizadas pelo trabalho realizado na Educação Infantil. Vinte e oito participantes salientaram estar satisfeitas com a profissão, mesmo conhecendo as dificuldades inerentes ao magistério. Com relação à profissão de professora dessa modalidade de ensino, nove regentes disseram acreditar ser uma função muito estressante. Nesse sentido, dezenove participantes afirmaram que o trabalho pedagógico na Educação Infantil é excessivamente mais exigente que nas demais modalidades de ensino, portanto, deveria ser mais bem remunerado. Morettini (2000, p. 24, grifo do autor) destaca que:

[...] a respeitabilidade que envolve a profissão de professor deve-se ao aspecto não manual de sua atividade, que desde a primeira divisão social do trabalho, quando a atividade intelectual se separou do trabalho pesado, tido como degradante e indigno. O professor aceita essa dignidade que envolve o seu trabalho, em troca de uma recompensa que não é material - o professor trabalha para "o bem". Nesse sentido, reside também na finalidade da tarefa, a especificidade de seu trabalho.

Mesmo conhecendo todas as dificuldades inerentes ao magistério, a maioria das participantes está satisfeita com a profissão que escolheu e apenas uma dentre as regentes afirmou que deixará a Educação Infantil quando conseguir outro emprego.

\subsection{0 trabalho pedagógico}

De acordo com a opinião das participantes, existem alguns atributos que o professor de Educação Infantil deve ter, e a formação específica para atuar nessa 
modalidade foi o ponto mais citado. Para a maioria das participantes, o profissional que atua na Educação Infantil deve sempre buscar capacitação. Nesse sentido, Morettini (2000, p. 45, grifo do autor) afirma que:

Expressões como a escola é a extensão do lar; a professora é a segunda mãe ou a tia; a professora é a jardineira a criança é a sementinha (herança dos jardins de infância froebianos) sempre povoam o universo da Educação Infantil, impregnando-a de preconceitos e estabelecendo nessa área (mais que nas outras) a predominância do emocional, do pessoal.

Gostar de crianças, ter paciência, ser sensível, foram outras características apresentadas como atributos que deve ter esse profissional.

$\mathrm{Na}$ opinião das professoras, existem algumas dificuldades ao assumir uma nova turma de Educação Infantil, e a maioria concordou que a realização do diagnóstico inicial seja o ponto mais difícil. Conhecer e perceber as particularidades de cada criança apareceu como segunda dificuldade que um professor enfrenta na sala de aula. Em terceiro lugar, citaram a falta de limites das crianças.

Quando avaliaram a qualidade do trabalho que os demais professores desenvolvem com as crianças na escola, todas as entrevistadas responderam que o trabalho é muito bom. Uma participante afirmou que a qualidade do trabalho "é muito boa, diria até excelente. Todos trabalham coletivamente para o crescimento do aluno".

Na opinião de sete participantes, a escola integral é pedagogicamente benéfica ao desenvolvimento global do aluno; as demais discordam. Três professoras afirmaram que a escola de horário integral é interessante para as famílias de menor poder aquisitivo.

A maior parte das professoras afirmou que participa da elaboração do Planejamento Pedagógico da escola onde trabalha. Cinco docentes, no entanto, responderam que não participaram da elaboração do documento. Para Libâneo (1994, p. 96), em relação a esse aspecto: 
A metodologia do trabalho docente inclui, pelo menos, os seguintes elementos: os movimentos (ou passos) do processo de ensino no decorrer de uma aula ou unidade didática; métodos, formas e procedimentos de docência e aprendizagem; os materiais didáticos e as técnicas de ensino; a organização da situação de ensino.

Outro aspecto analisado foi quanto às atividades relacionadas às datas comemorativas. Onze profissionais responderam que todas as atividades relacionadas às comemorações que envolvem decoração das instalações da escola devem ser realizadas pelas crianças, sob a supervisão dos professores. Três, dentre todas as professoras, afirmaram que parte das atividades deve ser feita pelos professores. Nesse sentido, todas as docentes concordaram não ser perda de tempo ou exploração delas como profissionais trabalhar na decoração da sala de aula e da escola nas festividades.

Para as entrevistadas, as escolas onde atuam não adotam a pedagogia tradicional, dando assim mais liberdade à criatividade do professor. Conforme leciona González Rey (2009, p. 133), ao se referir à teoria de Vigotski:

[...] o aprender pode, desse ponto de vista, passar a ser compreendido como produção e não como reprodução, o que representaria uma mudança radical nas formas em que a aprendizagem está institucionalizada hoje [...].

Afirma ainda o autor que “[...] a aprendizagem não é uma reprodução objetiva de conteúdos 'dados', é uma produção subjetiva que tem a marca do sujeito que aprende" (GONZALEZ REY, 2009, p. 133).

Para vinte e seis participantes, o trabalho pedagógico com crianças exige muito equilíbrio emocional por parte do professor; e para cinco delas, não há apoio da coordenação escolar nesse sentido.

Doze professores disseram acreditar que a prática docente desenvolvida na escola seja suficiente para a formação dos alunos. Vinte e duas participantes opinaram que se tivessem assistência pedagógica na escola para atender aos alunos, o trabalho em sala de aula fluiria de forma mais eficiente. 
Em relação aos gestores escolares, dez professoras afirmaram que eles não facilitam o trabalho docente, sendo que seis profissionais salientaram que a coordenação pedagógica não se preocupa em acompanhar os professores, desempenhando o trabalho de forma burocrática. Para Libâneo, Oliveira e Toschi (2005, p. 339), a gestão democrática:

[...] não pode ficar restrita ao discurso da participação e suas formas externas - as eleições, as assembleias e as reuniões. Ao contrário, ela deve estar a serviço dos objetivos do ensino, especialmente da qualidade cognitiva dos processos de ensino-aprendizagem.

Apenas sete participantes afirmaram que as escolas onde atuam dispõem de apoio de outros profissionais como, por exemplo, nutricionista e psicólogo.

Quanto à supervisão das tarefas escolares pelos pais, apenas uma participante afirmou que este acompanhamento atrapalha as atividades em sala de aula. Vinte e cinco entrevistadas disseram que onde trabalham são motivadas a desenvolver projetos pedagógicos, com autonomia para a escolha dos temas. Cinco participantes afirmaram que não são motivadas. Dezesseis afirmaram que os pais estão sempre presentes nas reuniões escolares e seis participantes registraram que o professor da escola integral é menos produtivo devido ao desgaste físico e mental.

No trabalho pedagógico, foram observados os projetos desenvolvidos e aplicados à Educação Infantil. Vinte e oito professoras disseram desenvolver esses projetos na rotina da sala de aula, e duas regentes não responderam a essa pergunta. As professoras que trabalham com projetos citaram alguns, como por exemplo: Hora do Conto; Projeto Boneca Contadora de Histórias; Valorizando as Diferenças; Cidadania não tem idade e Projeto Alimentação Saudável.

\subsection{A realidade escolar}

Em relação à idade das crianças sob a responsabilidade do professor, vinte e seis entrevistadas não responderam a esta pergunta e três declararam ser responsáveis por crianças entre quatro e cinco anos. Uma docente registrou que leciona 
em escola que tem Educação Infantil e Ensino Fundamental, na qual ela atende a crianças entre quatro e quatorze anos.

Quando questionadas a respeito da estrutura e dos recursos didáticos presentes na escola necessários ao desenvolvimento e à aprendizagem dos alunos, grande parte das professoras afirmou que a escola os tem e os utiliza adequadamente. Apenas três participantes afirmaram que a instituição não trabalha com este suporte, pois não os tem de forma adequada, e que tudo o que existe na escola é muito precário. Uma docente desabafou dizendo que, "muitos recursos adquiro com meu próprio salário, como, por exemplo, jogos”. De acordo com o Referencial Curricular Nacional para a Educação Infantil, em seu volume 2 (BRASIL, 2011c, p. 62):

[...] a oferta permanente de atividades diversificadas em um mesmo tempo e espaço é uma oportunidade de propiciar a escolha pelas crianças. Organizar, todos os dias, diferentes atividades, tais como cantos para desenhar, para ouvir música, para pintar, para olhar livros, para modelar, para jogos de regras etc., auxilia o desenvolvimento da autonomia.

Quanto aos recursos didáticos disponíveis, seis professoras disseram acreditar não serem suficientes para o desenvolvimento das competências e das habilidades previstas no planejamento pedagógico. As demais afirmaram que a escola tem recursos suficientes.

Vinte e três participantes afirmaram que a escola onde atuam promove a formação continuada de seus professores, sendo que sete, da mesma escola, negaram tal afirmação. Em referência à formação continuada Morettini (2000, p. 12) afirma que:

[...] no desempenho diário da profissão, a professora pré-escolar vai adquirindo conhecimentos, concepções elaboradas nos diferentes espaços de aprendizagem, em cursos de preparação para o Magistério ou na formação em serviço, em leituras e discussões em grupo, nas vivências do ensino, nas relações com os colegas e com os alunos, enfim, nas tantas relações sociais estabelecidas.

Quatorze docentes sustentaram que são incentivadas a buscar por informações e a atuar com independência. 
Para dezesseis participantes, a escola onde atuam não interage com os órgãos ligados aos direitos da criança e quatorze responderam que na instituição de ensino na qual trabalham existe essa vinculação. Vinte e duas participantes deixaram claro que os pais devem acompanhar diariamente as tarefas dos filhos e vinte e duas entrevistadas entendem que estão preparadas para receber sugestões dos pais em relação às práticas pedagógicas aplicadas.

\subsection{As relações interpessoais}

No ambiente escolar, as relações interpessoais acontecem em vários contextos. Tem-se a relação professor-aluno; aluno-aluno; professores-responsáveis e professor-coordenação da escola. Dependendo da postura da instituição escolar, os conflitos decorrentes dessas relações podem ser trabalhados positivamente, havendo ou não crescimento de todos os envolvidos, gerando desconforto e insegurança para as famílias e profissionais da escola. Morettini (2000, p. 22) escreve que

[...] rever a atividade docente significa rever o professor em suas relações sociais, tanto na especificidade da tarefa que ele realiza como nas manifestações reveladas pelo grupo ao qual pertence e pela sociedade como um todo.

No ambiente da sala de aula de Educação Infantil, as professoras apresentaram as principais dificuldades de relacionamento, sendo a falta de limites das crianças o ponto mais citado entre as participantes que entendem ser esta a maior dificuldade da relação professor-aluno. A agressividade e a adaptação também foram citadas, mas, para uma docente, não há problemas na relação professor-aluno, pois as crianças são dóceis e a têm como exemplo.

$\mathrm{Na}$ relação aluno-aluno, grande parte das participantes concordou que o egocentrismo é a maior dificuldade do inter-relacionamento entre as crianças. A socialização dos alunos foi outro ponto citado.

Na relação professores-responsáveis, doze participantes atestam que a maior dificuldade está na falta de participação, de cooperação e de parceria da família com a escola. Uma professora observa que a minoria dos pais participa da 
vida escolar do filho. Outro aspecto levantado pelas docentes é quanto ao equívoco de algumas famílias ao considerarem a professora como babá, não valorizando o trabalho que é desenvolvido em sala de aula. Para uma das professoras, os pais confundem muito o trabalho das docentes com o trabalho de "cuidadores". Para essas participantes, as famílias têm uma percepção limitada do trabalho realizado na Educação Infantil. Em relação a isso, Morettini (2000, p. 45, grifo do autor) afirma que:

[...] o sentido da afetividade passou a ser visto de uma maneira inadequada, fator que ajudou na caracterização da professora de crianças pequenas como apenas "mãe", numa postura que o aspecto afetivo aparece dissociado do cognitivo e pela qual ela não precisaria ser competente.

Quatro docentes veem a participação dos pais ou da família como não colaboradora no sucesso do processo ensino-aprendizagem. As demais creem que essa participação é, sim, importante. Todas as professoras afirmaram que os pais têm formação para interferir no trabalho da escola.

Enquanto três participantes salientaram que os pais não devam colaborar na parte de eventos e conservação da escola; oito participantes afirmaram que os pais não devem participar diretamente, mas precisam intervir, quando necessário, no projeto político-pedagógico da escola.

Na relação entre professor e coordenação, dez professoras afirmaram que não existem dificuldades de relacionamento, e uma docente citou sua experiência, mostrando que na escola onde atua, sempre há diálogo e que, por isso não existem dificuldades. Para seis participantes, a falta de apoio é a maior dificuldade entre docentes e coordenação.

Outro ponto analisado nessa categoria, no qual as participantes deveriam afirmar sim ou não, é se a escola em que atuam promove o relacionamento harmonioso entre os profissionais, melhorando o processo de ensino e aprendizagem. Vinte e sete docentes afirmaram que sim, que a escola promove esse relacionamento harmonioso enquanto três afirmaram que não. 
A maioria das participantes disse acreditar que as relações interpessoais na escola determinam a qualidade do trabalho pedagógico e que, por esse motivo, professores, diretores e coordenadores devem primar pelo convívio harmônico, minimizando a competição. Apenas três regentes discordam dessa afirmação. Segundo Morettini (2000, p. 23):

[...] as professoras constituem-se no transcurso de suas trajetórias, através da apropriação da cultura historicamente acumulada, processo que acontece em gradual interiorização do externo, do social e a sua transformação em interno, individual. Esse processo produz-se na comunicação e nas relações sociais que as professoras estabelecem nos diferentes grupos que participam, na atividade que realizam, de acordo com as suas condições objetivas de vida.

Uma professora assegura que não existe troca de experiências na escola onde trabalha, enquanto que, para as demais participantes, na instituição onde atuam, há troca de ideias e de experiências para enriquecer o trabalho pedagógico da escola.

Quando questionadas acerca do posicionamento que a escola deve ter em referência ao relacionamento harmonioso entre profissionais, família e alunos, três participantes sustentam não haver tal posicionamento na escola onde trabalham.

\subsection{A formação para o trabalho}

Após análise dos questionários, constatou-se que duas docentes concluíram apenas o curso magistério, dez concluíram a graduação e dezoito cursaram pósgraduação.

Em relação ao tempo decorrido desde a conclusão do último curso, técnico ou superior, foram obtidos os seguintes dados: onze participantes terminaram o curso há cinco anos; doze formaram-se entre seis e quinze anos atrás, e duas, há mais de dezesseis anos. Cinco participantes não responderam a pergunta.

Em relação ao tempo de experiência dos professores na Educação Infantil, verificou-se que doze regentes tinham até cinco anos de experiência, doze tinham 
entre seis e quinze anos, e cinco participantes, mais de dezesseis anos de experiência. Uma participante não respondeu a pergunta.

As participantes foram questionadas acerca dos cursos realizados na área de Educação Infantil e todas afirmaram que fizeram pelo menos um curso.

Durante o curso de graduação, quatorze entrevistados afirmaram que não foram preparadas adequadamente para atuarem nessa modalidade de ensino. As demais participantes afirmaram que havia preocupação por parte das instituições formadoras em prepará-las para lidarem com os problemas do dia a dia da Educação Infantil. Saviani (2009, p. 154) aponta que:

[...] com um quadro de professores altamente qualificado e fortemente motivado trabalhando em tempo integral numa única escola, estaremos formando os tão decantados cidadãos conscientes, críticos, criativos, esclarecidos e tecnicamente competentes para ocupar os postos do fervilhante mercado de trabalho de um país que viria a recuperar, a pleno vapor, sua capacidade produtiva. Estaria criando, por esse caminho, o tão desejado círculo virtuoso do desenvolvimento.

Quando questionadas a respeito da relação entre o que é ensinado no curso de Pedagogia e a realidade encontrada nas escolas, as opiniões das professoras ficaram divididas. Quinze afirmaram que existe uma longa distância entre a teoria ensinada nas graduações e a prática vivenciada em sala de aula. As demais participantes afirmaram que o curso de Pedagogia forneceu a base necessária para a prática em sala de aula.

Outro ponto de análise foi quanto à necessidade que os professores sentem de uma melhor formação para desenvolverem um bom trabalho pedagógico na escola em que atuam. Doze profissionais afirmaram que estavam nessa situação, dezoito docentes encontravam-se satisfeitas com sua preparação, e vinte e uma participantes declararam que sempre participam de cursos voltados para a Educação Infantil. Seis docentes concordam que as teorias ou tendências pedagógicas estudadas durante a graduação nada têm a ver com a realidade escolar. Segundo Pinto (2005, p. 50): 
Evidencia-se, nesse contexto, a necessidade de se dedicar atenção especial à orientação dos professores, por meio de cursos de formação que priorizem a relação teoria-prática, num espaço de construção coletiva de conhecimento possibilitando o desenvolvimento de competências necessárias a sua atuação profissional, com vistas a favorecer o desenvolvimento integral do educando e o sucesso do processo de ensino-aprendizagem.

Dezessete professoras disseram acreditar ser o mais indicado para os profissionais que atuarão na Educação Infantil.

\section{Reflexões finais}

Pode-se perceber, por meio deste trabalho no que tange à formação acadêmica dos docentes das escolas públicas, que duas professoras concluíram apenas o Magistério, dez concluíram a graduação e dezoito participantes concluíram a pós-graduação, o que possibilita a conclusão de que os professores da escola pública de Educação Infantil estão preparados para a docência. Todas as participantes fizeram pelo menos um curso na área de Educação Infantil e seis afirmaram que as teorias ou tendências pedagógicas estudadas durante a graduação nada tinham a ver com a realidade escolar em que atuam. Dezoito docentes encontravam-se satisfeitas com a preparação que tinham recebido para o magistério e vinte e uma entrevistadas declararam que sempre participam de cursos voltados para a Educação Infantil.

Em relação ao tempo de experiência das participantes, verificou-se que a maioria encontrava-se com mais de quatro anos na regência nessa modalidade de ensino. O trabalho pedagógico com crianças, segundo vinte e seis participantes, exige muito equilíbrio emocional por parte do professor.

Foi importante perceber que, apesar de todas as dificuldades inerentes ao magistério e vivenciadas pelos professores, a maioria das participantes está satisfeita com a profissão que escolheu e apenas uma regente afirmou que deixará a Educação Infantil quando conseguir outro emprego. Entretanto, dezenove participantes afirmaram que o trabalho pedagógico na Educação Infantil é bem mais exigente que o dos demais níveis de ensino e que deveria, portanto, ser mais bem remunerado. 
As principais características e atributos de um professor de Educação Infantil destacados pelas participantes foram: gostar de crianças, ter paciência, ser sensível e ter formação adequada para a atuação. Com relação ao trabalho pedagógico, vinte e oito professoras afirmaram desenvolver projetos pedagógicos na rotina da sala de aula.

Os participantes consideraram ser fundamental a participação da família na elaboração e na intervenção do projeto político-pedagógico da escola, mas não contam sistematicamente com a presença delas nas reuniões escolares. Vinte e seis entrevistadas afirmaram que os pais recebem indicativos da importância da sua participação na escola. Quanto à participação dos pais, quatro docentes disserem acreditar que a participação da família não colabora para o sucesso do processo ensino-aprendizagem. Os demais creem que a participação dos pais seja importante. Todos as professoras afirmaram que os pais têm formação para interferir no trabalho da escola.

Quanto à estrutura e funcionamento da escola, três participantes afirmaram que a instituição onde atuam não oferece condições necessárias ao desenvolvimento do trabalho pedagógico, mas os demais salientaram que na instituição existem condições necessárias ao trabalho. Dezesseis participantes afirmaram que a escola onde atuam não tem vínculos com órgãos ligados aos direitos da criança e quatorze afirmaram que ela tem, sim, esta vinculação.

Pelos dados apresentados, percebeu-se que não há dificuldades de relacionamento entre professores e coordenadores e vinte e sete docentes afirmaram que a escola promove um relacionamento harmonioso entre os profissionais. A maioria dos participantes afirmou acreditar que as relações interpessoais na escola determinam a qualidade do trabalho pedagógico e, por isso, professores, diretores e coordenadores devem primar pelo convívio harmônico, minimizando a competição.

Considerou-se que, pelo número de participantes na pesquisa, pode-se estabelecer uma percepção indicativa da situação da Educação Infantil no Distrito Federal. 
Esta pesquisa faz parte de uma pesquisa maior que abrange também a participação de gestores e pais, tanto de escolas públicas quanto das escolas particulares, e professores de escolas particulares. Todos esses dados, reunidos, aprofundarão os resultados da pesquisa, uma vez que se pretende, ao final, obter resultados contributivos para melhoria do processo de formação do educador no Distrito Federal e a divulgação dos resultados em eventos e em periódicos científicos, em nível regional, nacional e internacional.

\section{Feelings of early childhood education teachers in Public Schools}

\section{Abstract}

This paper presents the results of a study on teachers' feelings concerning expectations and requirements for Early Childhood Education in Federal District public schools. The qualitative method was applied, having a questionnaire as basic tool. The outcome was that teachers are prepared to teach, and pleased with their chosen profession. How to perform the initial class diagnosis was one of the difficulties pointed out by teachers, who believe that harmonious interpersonal relations among teachers, headmasters, coordinators, parents and students may determine the good quality of pedagogical work. It is hoped that this study may lead to greater concern and consideration about teaching in Early Childhood Education.

Keywords: Early childhood education. Pedagogical practice. Public school. Teacher training.

\section{Referências}

BRASIL. Constituição (1988). Constituição da República Federativa do Brasil Disponível em: <http://www.planalto.gov.br/ccivil_03 /constituicao/ constitui\%C3\%A7ao.htm>. Acesso em: 02 jun. 2011.

BRASIL. Ministério da Educação. Lei de Diretrizes e Bases da Educação Nacional LDB n 9.394/96. Disponível em: <http://portal.mec.gov.br>. Acesso em: 21 mar. 2011. 
BRASIL. Referencial Curricular Nacional para a Educação Infantil. Disponível em: <http://www.gestaodeconcurso.com.br/site/cache/1e658f45-9080-48e9-a55de4d0189c133e/referencial\%20curricular\%20nacional \%20para\%20educacao \%20 infantil \%20vol1.pdf>. Acesso em: 19 abr. 2011.

GONZÁLEZ REY, Fernando. Pesquisa qualitativa e subjetividade: os processos de construção da informação. São Paulo: Thomson, 2005.

GONZÁLEZ REY, Fernando. Questões Teóricas e Metodológicas nas Pesquisas sobre a Aprendizagem: a aprendizagem no nível superior. In: MARTINEZ, Albertina Mitjáns; TACCA, Maria Carmen Villela Rosa (Org.). A complexidade da aprendizagem: destaque ao ensino superior. Campinas: Alínea, 2009.

LIBÂNEO, José Carlos de; OLIVEIRA, João Ferreira; TOSCHI, Mirza Seabra. Educação escolar: políticas, estrutura e organização. São Paulo: Cortez, 2005.

LIBÂNEO, José Carlos. Didática. São Paulo: Cortez, 1994.

MORETTINI, Marly Teixeira. Professoras de educação infantil: personagens que se constituem no movimento de suas trajetórias. Campo Grande: UFMS, 2000.

PINTO, Celeida B. Garcia Cintra. A formação continuada do professor e o sucesso do processo ensino-aprendizagem. Universitas, Brasília, v.2, n.1, p. 47-52, jan./jun. 2005.

SAVIANI, Dermeval. Formação de professores: aspectos históricos e teóricos do problema no contexto brasileiro. Revista Brasileira de Educação, v. 14, n. 40, jan./ abr. 2009. 


\section{Para publicar na revista Universitas Humanas, acesse 0 endereço eletrônico www.publicacoesacademicas.uniceub.br. Observe as normas de publicação, para facilitar e agilizar o trabalho de edição.}

